\title{
Thermal analysis of Double Stator Switched Reluctance Machine (DSSRM) with and without a squirrel cage rotor
}

\author{
Mohammadali Abbasian ${ }^{1}$, Hadi Jalali ${ }^{2}$ \\ ${ }^{1}$ Department of Electrical and Computer Engineering, Khorasgan Branch, Islamic Azad University \\ P.O. Box 81595-158 Isfahan, Iran \\ ${ }^{2}$ Department of Electrical Engineering, Khomeinishahr Branch, Islamic Azad University \\ P.O. Box 84175-119 Isfahan, Iran \\ e-mail: \{m.abbasian/hadi.jalali\}i@iaukhsh.ac.ir
}

(Received: 26.09.2016, revised: 18.11.2016)

\begin{abstract}
Double Stator Switched Reluctance Machine (DSSRM) is a novel switched reluctance machine with limited information about its heat distribution and dissipation. This paper presents a two dimensional (2-D) thermal analysis of Double Stator Switched Reluctance Machine (DSSRM) to observe actual heat distribution in the parts of the machine, using Finite Element Method (FEM). Two topologies for the rotor of DSSRM are considered, Non-Squirrel Cage Double Stator Switched Reluctance Machine (NSCDSSRM) and Squirrel Cage Double Stator Switched Reluctance Machine (SC-DSSRM). The heat distribution of these two topologies is analyzed, using Computational Fluid Dynamics (CFD). Finally the results are presented and compared.
\end{abstract}

Key words: Computational Fluid Dynamics (CFD), Finite Element Method (FEM), squirrel cage, double stator, switched reluctance machine, thermal analysis

\section{Introduction}

The losses in electrical machines generate heat. As a result, temperature of the different parts of the machine rises [1]. It actually decreases the life time of the machine and may even lead to the machine failure [2]. Therefore, thermal modeling and analyzing, plays an important role in the optimal design of electrical machines.

Double Stator Switched Reluctance Machine (DSSRM) is a novel electrical machine with limited information about heat dissipation which makes thermal analysis an essential stage for its design. DSSRM is designed to perform at high torque levels. It is a good candidate for industrial applications operating under harsh environment because it carries the SRM qualities, combining them with the advantages of the double stator topology [3]. As shown in Fig. 1, this machine benefits from two stators which are made of laminated ferromagnetic material and 
are equipped with concentrated windings. They are located on the interior and exterior of a cylindrical rotor. The rotor is formed by segments which are hold together using a non-ferromagnetic cage. The cross section of a 4-phase 8/6 DSSRM is illustrated in Figures 2 and 3.

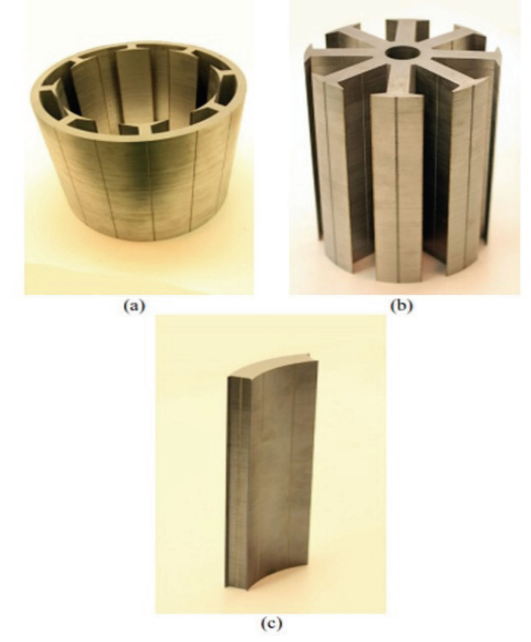

Fig. 1. Outer stator (a), inner stator (b), one rotor segment [7] (c)

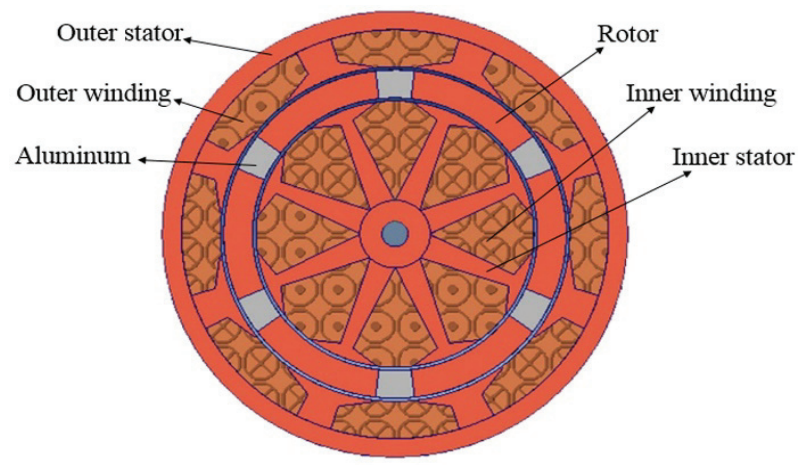

Fig. 2. Squirrel Cage Double Stator Switched Reluctance Machine (SC-DSSRM)

The inner stator of DSSRM is surrounded by the cylindrical rotor and it causes limitation for heat dissipation of the inner stator windings. So, it is necessary to consider the effect of rotor topology in the heat transfer of this machine.

There are two ways to connect the rotor to the output shaft of DSSRM. The first method is implementing a cage. In this method, the rotor segments are placed in a cage and the torque is transmitted to the output shaft by this cage. This topology is named: Squirrel Cage Double Stator Switched Reluctance Machine (SC-DSSRM).

In the second method, their rotor segments are connected together without any cage. In fact, there are two end-plates at either end of the rotor which keeps the rotor segments connected to the shaft. This topology is called: Non-Squirrel Cage Double Stator Switched Reluc- 
tance Machine (NSC-DSSRM). Now the main question is that which of these two topologies is better in terms of heat transfer for DSSRM.

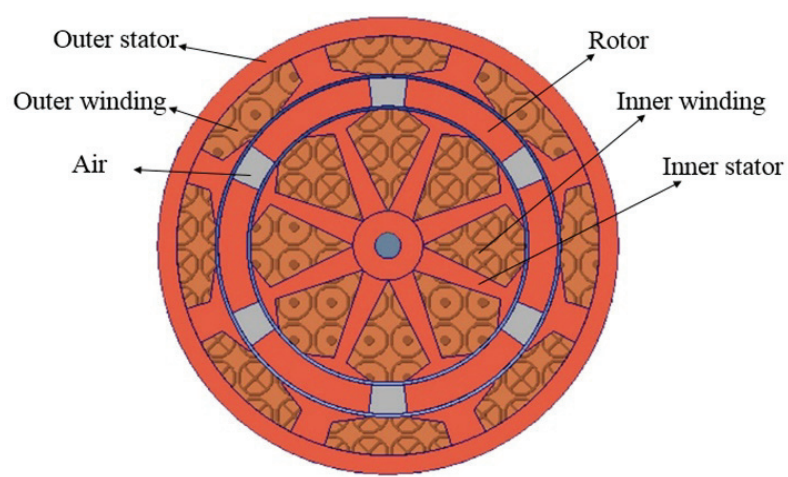

Fig. 3. Non-Squirrel Cage Double Stator Switched Reluctance Machine (NSC-DSSRM)

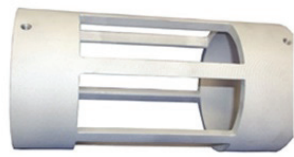

(a)

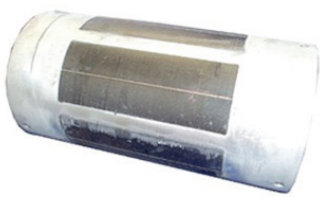

(b)

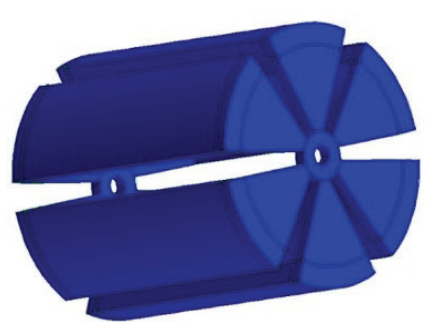

Fig. 4. Squirrel cage for the rotor of DSSRM (a), the rotor of SC-DSSRM (b)

Fig. 5. Rotor of NSC-DSSRM

In [4], thermal modeling and analysis of a $10 \mathrm{~kW}$ DSSRM are presented and the temperature distribution in different parts of the machine (including the use of water as coolant) is calculated using FEM. In this paper the heat distribution of two different topologies of DSSRM is studied. The first topology is Non-Squirrel Cage Double Stator Switched Reluctance Machine (NSC-DSSRM) and the second one is Squirrel Cage Double Stator Switched Reluctance Machine (SC-DSSRM). The operation principle of NSC-DSSRM is similar to that of SC-DSSRM 
(see Figs. 2-5). The only difference between these two machines is in the design of the rotor. Implementation of the cage in the rotor of DSSRM may influence the heat distribution of the machine, which is studied in this paper using Computational Fluid Dynamics (CFD) [5].

In order to have a more accurate model, a lumped parameter thermal model for DSSRM is proposed in which both modes of heat transfer, conduction and convection are considered. The geometrical model of DSSRM is built up as a parametric model and the simulation results obtained from CFD [6] are presented for an 8/6 DSSRM whose specifications are presented in Table 1.

\section{Thermal analysis of Double Stator Switched Reluctance Machine}

\subsection{Geometrical model}

A two dimensional (2-D) model of DSSRM used in this study is shown in Fig. 6. The machine parameters are given in Table 1. The model consists of two stators, one rotor, two stator windings and two airgaps. Drawing the geometrical model of the machine can be a time-consuming task, especially if various different designs have to be investigated. Therefore, the geometrical model is created as a parametric model and mesh generation is done.

\subsection{Heat source}

The two main components of electromagnetic losses in DSSRM are core losses in the laminations and copper losses in the windings. These losses are the heat source in a thermal analysis [8]. Core losses in DSSRM machine are relatively low, because it benefits from a short flux path. The copper loss and core loss for the different parts of DSSRM are calculated when the rotor speed is $1000 \mathrm{rpm}$ and the phase current is $5 \mathrm{~A}$. The result are presented in Table 2. Moreover, average torque and torque ripple, stator ampere-turn and efficiency at the operating point are mentioned in Table 2. The phase current waveform is assumed as illustrated in Fig. 12 (see Appendix)

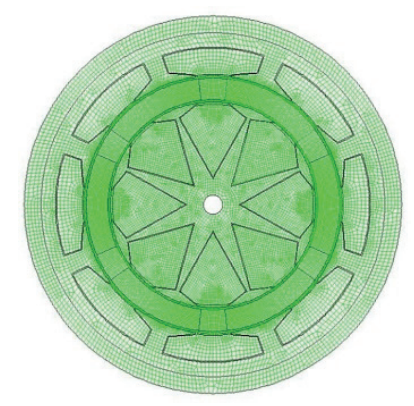

Fig. 6. 2-D Finite element model of DSSRM

In order to predict the temperature distribution in a stator and windings, the thermal analysis of DSSRM using FEM is proposed. Both natural and forced convection are considered for heat transfer through external surface of the machine. Heat transfer from the stator and 
windings to an airgap is modeled by forced convection due to the rotation of the rotor. The thermal parameters used in the analysis are given in Table 3.

\subsection{Winding model}

It is well known that the majority of electrical machines with wound-wire windings have random wire disposition inside the slots, so it is not possible or desirable to model the position of each individual conductor when carrying out thermal analysis. One approach to simplify the model is to use the equivalent thermal conductivity of the system windings and insulation which can be obtained by various methods such as analytical approach, FEM or experiments. Using the numerical and analytical methods an equivalent thermal conductivity of $0.80 \mathrm{~W} / \mathrm{m} /{ }^{\circ} \mathrm{C}$ is considered for the windings in the proposed thermal analysis.

\section{Simulation result analysis}

Considering a value of $4 \mathrm{~m} / \mathrm{s}$ for the air velocity over a frame, the forced convection coefficient over this surface is $30 \mathrm{~W} / \mathrm{m}^{2 \circ} \mathrm{C}$. It is noted that since the convection coefficients are rather low, heat transfer by radiation might be important when only natural convection for the external surfaces of the machine is considered in the thermal analysis. For example, it is $30 \mathrm{~W} / \mathrm{m}^{2 \circ} \mathrm{C}$, when the air velocity is $4 \mathrm{~m} / \mathrm{s}$. When the inside air temperature rise obtained for $h=30 \mathrm{~W} / \mathrm{m}^{2} \mathrm{C}$ is considered in the 2-D thermal analysis of the 8/6 DSSRM. For all thermal simulation results in the following external surface of the motor (frame) is $30 \mathrm{~W} / \mathrm{m}^{2}{ }^{\circ} \mathrm{C}$.

The ambient temperature is set as $20^{\circ} \mathrm{C}$ and thermal analysis was carried out. In the thermal analysis, the temperature increases and reaches the maximum temperature of $65.62^{\circ} \mathrm{C}$, at $1000 \mathrm{rpm}$. The different boundary conditions are shown in Fig. 7. The numeric solution for the thermal analysis is obtained over 140 hours using 8 processors on a Linux cluster with $2.2 \mathrm{GHz}$. In [10] the thermal analysis of DSSRM is presented in details.

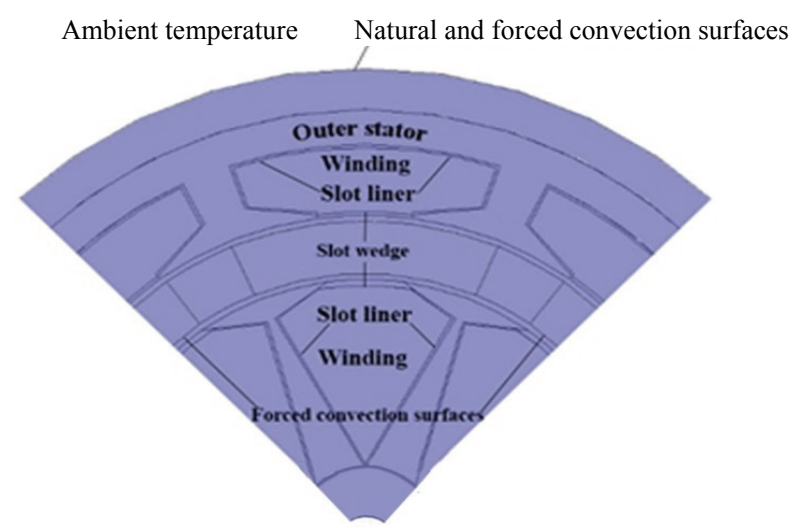

Fig. 7. Machine geometrical model in thermal analysis and different types of boundary conditions

\subsection{Analysis result of Squirrel Cage DSSRM (SC-DSSRM)}

Figures 8 and Fig. 9 represent the results of thermal analysis of SC-DSSRM. Figure 8 illustrates temperature distribution in the machine and Fig. 9 represents the temperature rise in 
different parts of the machine at $1000 \mathrm{rpm}$ and $5 \mathrm{~A}$. It is clear that the maximum temperature of $65.5^{\circ} \mathrm{C}$ occurs in the inner windings.

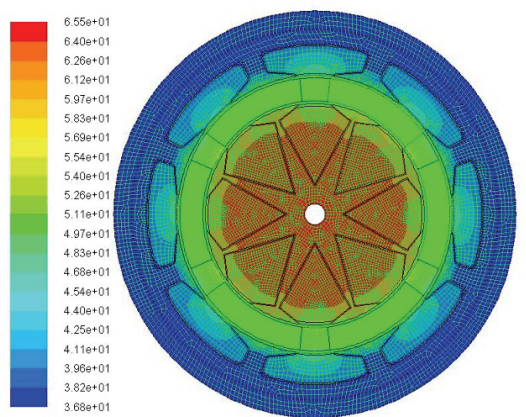

a)

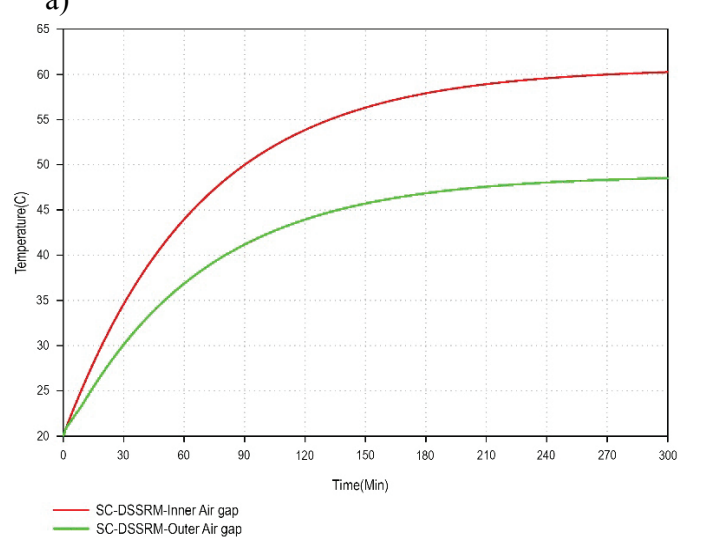

c)

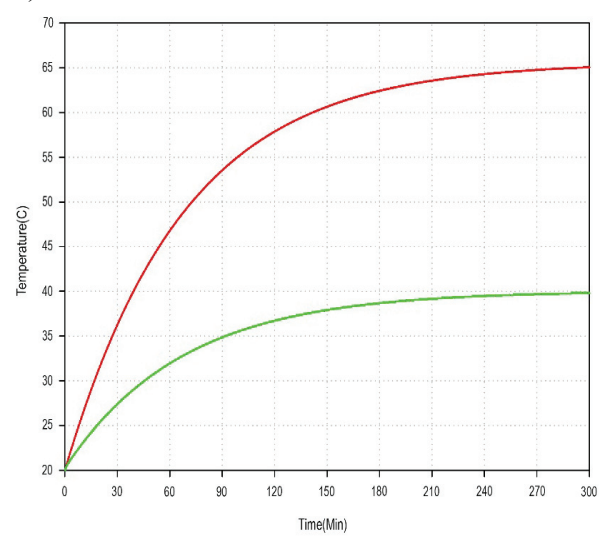

- SCDSSRM-Inner Stator
Fig. 8. Temperature distribution at $1000 \mathrm{rpm}$ for SC-DSSRM b)

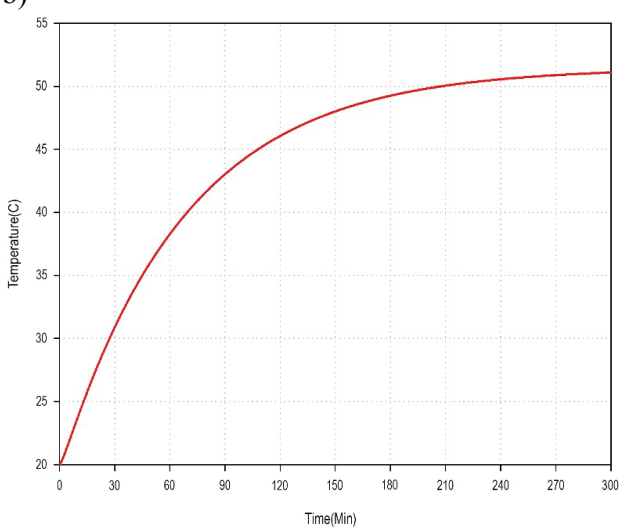

d)

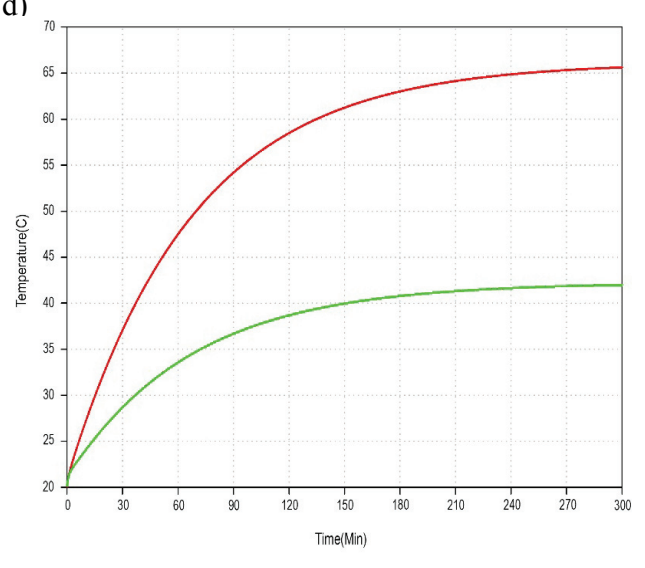

_ SCDSSRIM-nner Winding

Fig. 9. Temperature-time curve for SC-DSSRM: air gaps (a), rotor (b), stators (c), windings (d) 


\subsection{Analysis result of Non-Squirrel Cage DSSRM (NSC-DSSRM)}

Figures 10 and 11 represent the results of thermal analysis of SC-DSSRM. Figure 10 illustrates temperature distribution in the machine at $1000 \mathrm{rpm}$ and 5 A. Fig. 11 shows the temperature rise in different parts of the machine. It is clear that the maximum temperature of $69.5^{\circ} \mathrm{C}$ occurs in the inner windings.

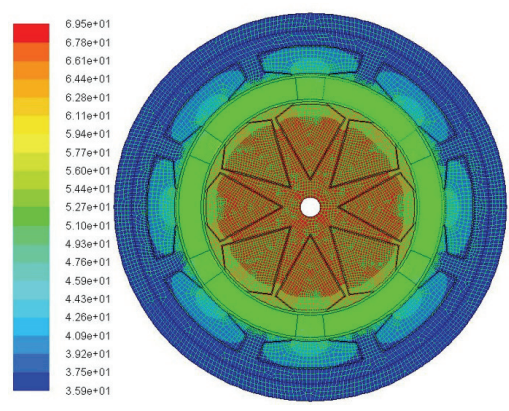

Fig. 10. Temperature distribution at $1000 \mathrm{rpm}$ for NSC-DSSRM

a)

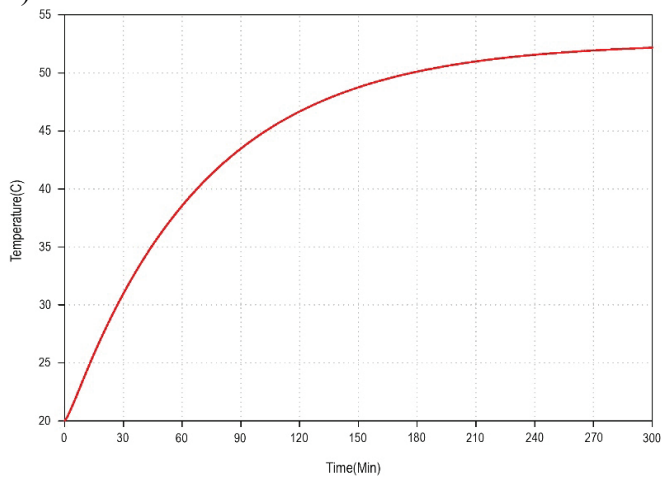

— NSC-DSSRM-Rotor

c)

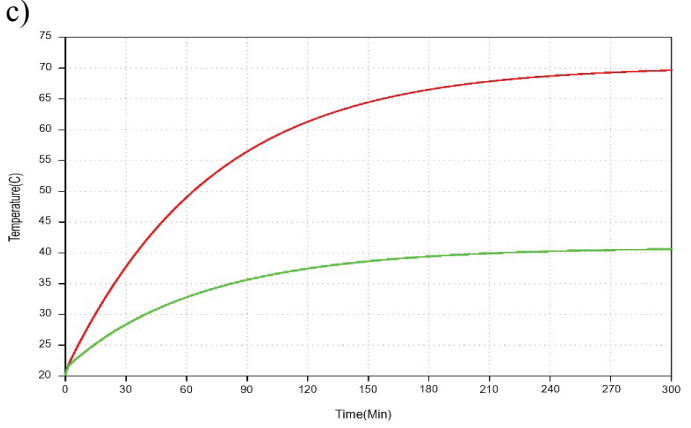

- NSC-DSSRM-Inner Winding b)

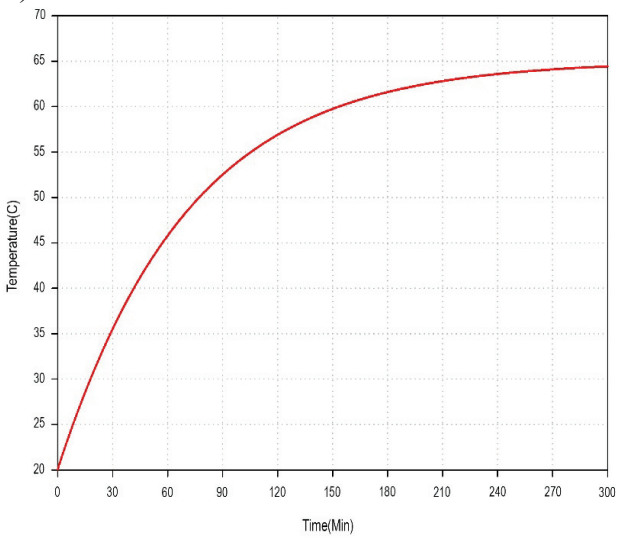

— NSCDSSRM-Airgap

d)

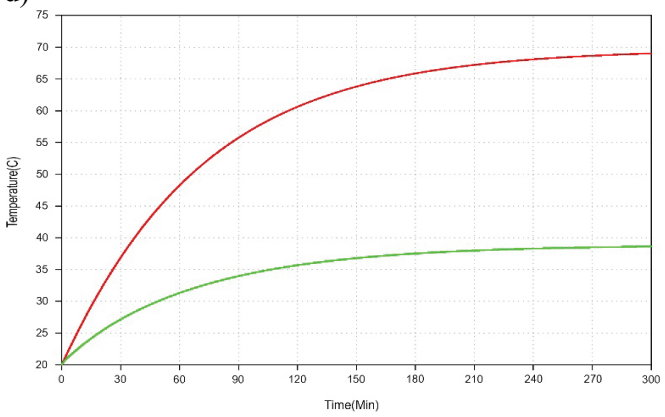

- NSC-DSSRM-Inner Stator

Fig. 11. Temperature-time curve for NSC-DSSRM: air gap (a), rotor (b), stators (c), windings (d) 


\section{Conclusion}

In this paper, the thermal analysis of Double Stator Switched Reluctance Machine (DSSRM) was done, using Finite Element Method (FEM). Two topologies for the rotor of DSSRM were considered: Non-Squirrel Cage Double Stator Switched Reluctance Machine (NSC-DSSRM) and Squirrel Cage Double Stator Switched Reluctance Machine (SC-DSSRM). The heat distribution of these two topologies was analyzed, using Computational Fluid Dynamics (CFD). It was shown that the temperature rise in SC-DSSRM is less, compared to NSCDSSRM. It can be concluded that the aluminum cage plays an important role in heat transfer of the inner stator winding.

\section{Appendix}

Table 1. Specifications of 8/6 DSSRM [3]

\begin{tabular}{l|c}
\hline No. of phases & 4 \\
\hline No. of stator/rotor poles & $8 / 6$ \\
\hline Outer radius of outer stator [mm] & 72.0 \\
\hline Outer radius of inner stator [mm] & 43.9 \\
\hline Rotor segment thickness [mm] & 9.0 \\
\hline Airgap & 1.0 \\
\hline Stack length [mm] & 115.0 \\
\hline Arc of the rotor [deg.] & 47 \\
\hline Turns per coil & 50 \\
\hline Resistance @ $20^{\circ} \mathrm{C}[\Omega]$ & 0.78 \\
\hline Rated speed of motor [rpm] & 1000 \\
\hline
\end{tabular}

Table 2. Operating point characteristics of DSSRM

\begin{tabular}{l|c}
\hline Stator ampere-turn & 750 \\
\hline Avarage torque & $4.76 \mathrm{Nm}$ \\
\hline Torque ripple & $1.29 \mathrm{Nm}$ \\
\hline Speed & $1000 \mathrm{rpm}$ \\
\hline Outer stator copper loss & $10.21 \mathrm{~W}$ \\
\hline Inner stator copper loss & $9.82 \mathrm{~W}$ \\
\hline Outer stator core loss & $3.76 \mathrm{~W}$ \\
\hline Inner stator core loss & $3.43 \mathrm{~W}$ \\
\hline Rotor core loss & $2.21 \mathrm{~W}$ \\
\hline Rotor cage loss & $9.63 \mathrm{~W}$ \\
\hline Efficiency (NSC-DSSRM) & $94.41 \%$ \\
\hline Efficiency (SC-DSSRM) & $92.71 \%$ \\
\hline
\end{tabular}


Table 3. Thermal parameters [9]

\begin{tabular}{l|c|c|c}
\hline & $\begin{array}{c}\text { Thermal } \\
\text { conductivity } \\
\left(\mathbf{w} / \mathbf{m} /{ }^{\mathbf{0}} \mathbf{C}\right)\end{array}$ & $\begin{array}{c}\text { Specific } \\
\text { heat } \\
\left(\mathbf{J} / \mathbf{k g} /{ }^{\circ} \mathbf{C}\right)\end{array}$ & $\begin{array}{c}\text { Density } \\
\left(\mathbf{k g} / \mathbf{m}^{\mathbf{3}}\right)\end{array}$ \\
\hline Stator lamination (iron) & 20 & 438 & 7650 \\
\hline Copper & 401 & 385 & 8933 \\
\hline Slot liner & 0.076 & 1172 & 2150 \\
\hline Air & 0.0263 & 1007 & 1.16 \\
\hline Frame (aluminum) & 177 & 875 & 2770 \\
\hline Slot wedge & 0.29 & 1172 & 2150 \\
\hline
\end{tabular}

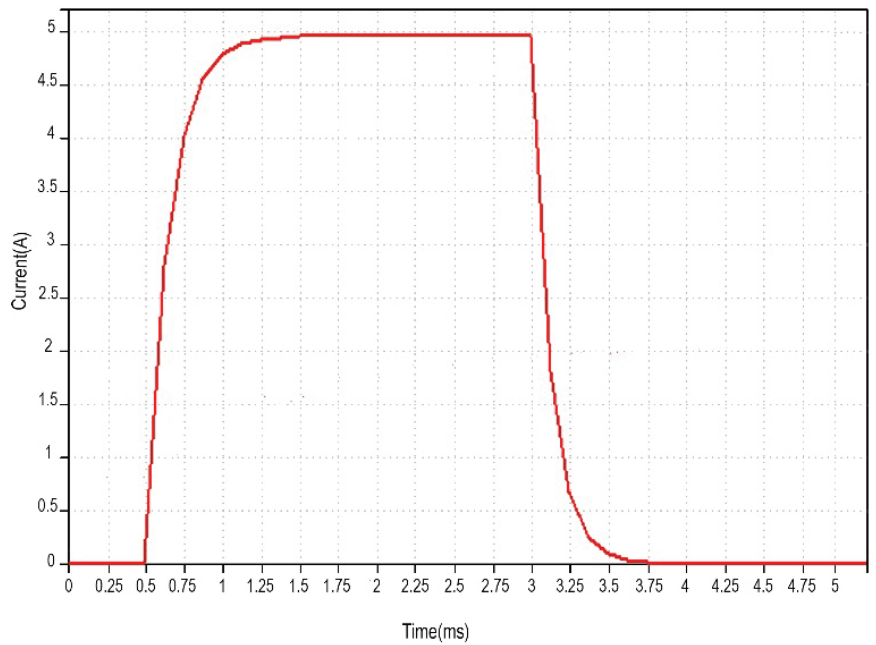

Fig. 12. Phase current waveform of DSSRM

\section{Refrences}

[1] Stone G.C., Culbert I., Edward A., Boulter and Hussein Dhirani, Electrical Insulation for Rotating Machines Design, Evaluation, Aging, Testing and Repair, Wiley (2004).

[2] Faiz J., Dadgari A., Heat distribution and thermal calculations for a switched reluctance motor, Journal of Electrical and Electronics Engineering, Australia, IE Australia \& IREE Australia, vol. 12, no (4),pp. 349-361(1992).

[3] Abbasian M., Moallem M., Fahimi B., Double Stator Switched Reluctance Machines (DSSRM): Fundamentals and Magnetic Force Analysis, IEEE Transaction on Energy Conversion, vol. 25, no. 3, pp. 589-597 (2010).

[4] Arbab N., Wang W., Lin C., Hearron J., Fahimi B., Thermal Modeling and Analysis of a DoubleStator Switched Reluctance Motor, IEEE Transaction on Energy Conversion, vol. 30, no. 3, pp. 1209-1217 (2015).

[5] Anderson J.D. Jr., Computational Fluid Dynamics, McGraw-Hill International Editions (1995).

[6] Wood S.E., Greenwood D., Force ventilated motors advantages in fixed variable speed application, Proceedings of 5th IECON, pp. 276-280 (1991). 
[7] Lin C., Wang W., Fahimi B., Optimal Design of Double Stator Switched Reluctance Machine (DSSRM), Industrial Electronics (ISIE) (2012).

[8] Trigeol J.F., Bertin Y., Lagonotte P., Coupling control volume modeling in fluid and lumped thermal model-Application to an inductionmachine, Proceedings of 6th IECON, pp. 4829-4834 (2006).

[9] Incropera F., DeWitt D., Fundamentals of Heat and Mass Transfer. New York: Wiley, (1990).

[10] Abbasian M., Jalali H., Temperature Distribution Analysis of Double Stator Switched Reluctance Machine Using Finite Element Method, Electrical Machines \& Power Electronics (ACEMP), Int. Conference on Optimization of Electrical \& Electronic Equipment (OPTIM) \& Int. Symposium on Advanced Electromechanical Motion Systems (ELECTROMOTION), Int. Aegean Conference on Electrical Machines \& Power Electronics, Ankara, Turkey (2015). 